NBER WORKING PAPER SERISS

\title{
INTEREST RATE VOLATILITY AND MONETARY POLICY
}

\author{
Carl E. Walsh
}

Working Paper No. 915

\author{
NATIONAL BUREAU OF ECONOMIC RESEARCH \\ 1050 Massachusetts Avenue \\ Cambridge MA 02138
}

June 1982

The research reported here is part of the NBER's research program in Financial Markets and Monetary Fconomics. The views expressed herein are solely those of the author and to not necessarily represent the views of the Federal Reserve Bank of Kansas City, the Federal Reserve System, or the National Bureau of Sconomic Research. 
NBER Working Paper \#915 June 1982

\title{
INTEREST RATE VOLATILITY AND MONETARY POLICY
}

\begin{abstract}
In October 1979 the Federal Reserve shifted from an interest rate oriented operating procedure to a reserves oriented procedure. It is argued in this paper that part of the very large increase in interest rate volatility which resulted from the policy switch may have been due to shifts in the parameters of the money demand equation, shifts due to the adoption of a reserve aggregates operating procedure. This result is derived by comparing rational expectations equilibria in a simple theoretical model under alternative policy rules. This allows the variance of interest rates to be explicitly expressed as a function of the policy rule.
\end{abstract}

Car1 E. Walsh

Department of Economics Princeton University Princeton, NJ 08544 (609) 452-4026 


\title{
INTEREST RATE VOLATILITY AND MONETARY POLICY
}

\author{
Carl E. Walsh*
}

\section{Introduction}

In October 1979, the Federal Reserve shifted from an interest rate oriented operating procedure to a reserves oriented procedure. One expected result of such a policy shift would be an increase in the short-run volatility of market interest rates, and this has occurred. However, the increase in interest rate fluctuations has been very large, much larger than was probably anticipated. According to a review of monetary control procedures carried out by the Federal Reserve staff (Tinsley and others [1981]), the standard deviation of monthly changes in the Federal funds rate increased from 0.27 in the year prior to the policy shift to 2.4 in the year following the shift. A simple theoretical model is used in this paper to argue that part of this increase may be due to shifts in the parameters of the money demand equation, with the parameter changes being due to the adoption of a reserves oriented operating procedure. This result is derived by comparing rational expectations equilibria under alternative monetary policy rules. This allows the variance of interest rates to be explicitly expressed as a function of the policy rule followed by the monetary authority.

The argument advanced in this paper is motivated by the following line of reasoning. Models of portfolio choice by risk averse asset holders imply that the demand for risky assets will depend upon the joint probability distribution of asset returns. In a mean-variance framework, this implies that the demand for money (and other assets) will be a function of both expected rates of return (on money and other assets) and the covariances 
among asset returns (Tobin [1958]). If the monetary authority changes the way in which it adjusts the money supply in response to shocks to the economy, the covariances between the rate of inflation and the returns on other assets will be affected. This will result in a shift in asset demand equations. Hence, the money demand function will change if the monetary authority shifts from an interest rate oriented policy to a money supply oriented policy.

The policy induced change in the demand for money function is not simply a change in the intercept; interest and income elasticities change. This means that the old money demand function cannot be used to draw inferences about the variance of interest rates after a change in the operating procedure. This, of course, is just another example of the Lucas [1976] policy evaluation critique.

Because variances and covariances become important when the money demand function is derived from an underlying portfolio choice model, the assumption of rational expectations imposes nonlinear restrictions on the parameters of the equilibrium expression for the interest rate. Market clearing implies a distribution function for the equilibrium rate of interest; in a rational expectations equilibrium this distribution must be identical with the one upon which asset demands are based. (See Lucas [1978].) By utilizing a model which allows the rational expectations equilibrium solution for the endogenous variables to be explicitly calculated, it is possible to discover how, for example, the variance of the interest rate depends upon the policy rule followed by the monetary authority. The standard approach to evaluating alternative policies, which assumes that 
the parameters of the money demand function are policy invariant, is shown to produce misleading conclusions. ${ }^{-}$/ In particular, a switch from a policy of stabilizing interest rates to one focusing on monetary aggregates will lead to greater interest rate volatility than is implied by the standard approach.

In order to demonstrate these points, this paper proceeds by first specifying a simple macroeconomic model in which the parameters of the money demand function are assumed to be policy invariant. Since expectations of prices and interest rates appear in the model, the assumption of rational expectations is used to obtain an equilibrium solution. This solution corresponds to the standard approach described above, and the implications derived from it provide a benchmark against which to compare subsequent results.

The next step is to show how the money demand function used in the basic model can be derived from a portfolio choice model. This exercise demonstrates how the parameters of the money demand function are themselves functions of the stochastic properties of the interest rate and the rate of inflation. The variance of the nominal price of bonds is, in the model used in this paper, the crucial variable in solving for the rational expectations equilibrium. In such an equilibrium, the variance of bond prices upon which individuals base their portfolio choices must agree with the bond price variance that is implied by the assumption of market clearing. This additional equilibrium requirement results in nonlinear restrictions on the solution parameters and raises the possibility of multiple solutions. Nonuniqueness in nonlinear rational expectations models has 
been discussed recently by McCafferty and Driskill [1980]. $2 /$ Similar problems arise in Walsh [1982]. In the present model, the variance of the price of bonds must satisfy a quadratic equation so that, in general, there are two solutions.

After deriving the solution for the model subject to the nonlinear restrictions implied by the rational expectations assumption applied to variances as well as means (hereafter referred to as the nonlinear model), the remainder of the paper discusses properties of the solution and compares them to the results derived under the standard approach in which the parameters of the money demand function are assumed to be policy invariant (hereafter referred to as the linear model). As has already been mentioned, a shift in policy from a rule which attempts to minimize the variance of bond prices to one which focuses on a monetary aggregate will lead to a larger increase in bond price (and hence interest rate) variation according to the nonlinear model than would be predicted by the linear model. It is also shown that the policy predicted by the linear model to minimize the variance of bond prices is, in fact, not the minimum variance policy. $\frac{3}{}$

In the next section the basic model is specified; at this stage, the portfolio balance function is not derived from an underlying portfolio choice model. Instead, it is simply assumed to be plausible, and its parameters are taken to be policy invariant. 4/ The rational expectations solution for this, the linear model, is derived in section III, while the properties of the solution are discussed in section IV. Section V attempts to show how the portfolio balance equation in the basic model could be derived from a mean-variance model of portfolio choice. One implication 
of this exercise is that the parameters in the portfolio balance equation are functions of the stochastic properties of the price of bonds and the price of money. The nonlinear restrictions this implies for the rational expectations solution are discussed in section VI. Section VII compares the results obtained in the nonlinear model with the predictions of the linear model. Finally, section VIII provides a summary of the paper's results. 
II. The Basic (Linear) Model

There are four equations in the model to be studied: an aggregate supply function, an aggregate demand equation, a portfolio balance condition, and a policy rule describing the actions of the monetary authority. Aggregate supply is assumed to be determined according to a Lucastype supply function in which the deviation of output from its "natural" level (in logs), $y_{t}-\bar{y}$, is related to deviations of the $10 \mathrm{~g}$ of the price leve1, $p_{t}$, from the value of $p_{t}$ that was expected at the end of previous period, ${ }_{t-1} P_{t}$. The most reasonable theoretical rationale for this type of supply function would seem to be that given by Fischer [1977]; labor contracts are set at the end of period $t-1$ on the basis of expectations concerning $P_{t}$ so that the labor market clears if $P_{t}={ }_{t-1} P_{t}$. As argued by Barro [1977], contracts of this nature are not Pareto optimal. In addition, there seems to be no empirical support for the Lucas supply function. Nevertheless, it has enjoyed wide usage in recent theoretical macroeconomics and does help to simplify the solution of many rational expectations models. Its ad hoc nature can only be defended by the lack of any superior alternatives. The aggregate supply relationship is assumed then to be

$$
y_{t}=\bar{y}+\alpha\left(p_{t}-{ }_{t-1} p_{t}\right)+\varepsilon_{t} ; \alpha>0,
$$

where $\varepsilon_{t}$ is a white noise supply shock (E$\left.\varepsilon_{t}=0, E \varepsilon_{t}^{2}=\sigma_{\varepsilon}^{2}, E \varepsilon_{t} \varepsilon_{s}=0, t \neq s\right)$.

Aggregate demand is assumed to depend upon the expected real return on bonds. If $s_{t}$ denotes the log of the nominal bond price at time $t$, this expected real return is given by $\left(s_{t+1}-s_{t}\right)-\left(t_{t+1}-p_{t}\right)$. The inclusion of this variable defers slightly from standard practice. Normally, bonds in 
macroeconomic models are assumed to be fixed price, variable rate bonds. Here, though, bonds are assumed for simplicity to yield only a capital gain. The expected real rate of interest requires, therefore, expectations both of the future price level $\left({ }_{t} p_{t+1}\right)$ and the future price of bonds $\left(s_{t+1}\right)$. In the portfolio problem considered in section $V$, it will be important that uncertainty about the real return to bonds involves uncertainty about both $s_{t+1}$ and $p_{t+1}$ and not $p_{t+1}$ alone. Demand is also subject to a mean zero, serially independent stochastic shock, $u_{t}$, with variance $\sigma_{u}^{2}$. Hence,

$$
y_{t}=k+\beta\left(s_{t+1}{ }^{-}{ }^{p} p_{t+1}-\left(s_{t}-p_{t}\right)\right)+u_{t} ; \beta<0
$$

The final equation modeling private sector behavior is a portfolio balance or money demand equation. If upper case letters denote levels of variables, $W$ real aggregate wealth and $M$ real money balances, the money demand equation is assumed to be $M_{t}=\left(\gamma_{0}+\gamma_{1} y_{t}+\gamma_{2}\left(s_{t+1}{ }^{-s_{t}}\right)\right) w_{t} ; \gamma_{1}>0 ; \gamma_{2}<0$. Defining $m_{t}$ as $M_{t} / W_{t}$, this equation can be rewritten as

$$
m_{t}=\gamma_{0}+\gamma_{1} y_{t}+\gamma_{2}\left(s_{t+1}-s_{t}\right)
$$

Three aspects distinguish equation (3) from a standard money demand equation. First, since the nominal return to bonds depends upon $s_{t+1}$, an expected nominal return variable appears in the demand for money function. Standard practice includes only an observed actual nominal interest rate thereby ignoring any expected capital gains or losses on bonds. Second, on the left-hand side of (3) appears the fraction of total wealth in the form of money rather than real money balances. This distinction will be important since it will be assumed that $\mathrm{m}_{t}$ is the policy variable controlled 
by the monetary authority. In other words, monetary policy consists of open market operations which alter the composition of the private sector's portfolio of bonds and money. Third, no stochastic disturbance term appears on the right-hand side of (3). Monetary disturbances will arise on the supply side only (in equation (4) below) through random fluctuations in $\mathrm{m}_{\mathrm{t}}$.

All three of these departures from a standard money demand equation are taken with a specific purpose in mind. In section V, I wish to demonstrate that (3) can be derived as the solution to a portfolio choice problem in which risk averse individuals maximize expected utility. Equation (3) is chosen to be so derivable and yet still look as much as possible like a standard money demand function.

The choice of $\mathrm{m}_{t}$ as the policy variable (rather than the nominal supply of money) has one very important implication: equations (1) - (3) cannot determine the absolute levels of either $\mathrm{p}$ or $\mathrm{s}$ since no one's behavior depends on the absolute level of either price. Only expected changes or expectational errors of $p$ and $s$ appear in these equations and both these types of terms are independent of arbitrary constants added to the solutions for $p$ and $s$. The levels of $p$ and $s$ will be determinate if they appear in the policy rule determining $m_{t}$ so that the policy authority's behavior depends upon the absolute level of $p$ or $s$. For example, if $m_{t}$ is based in part upon $\mathrm{P}_{t-1}$ and $\mathrm{s}_{t-1}$, this particular nonuniqueness problem disappears. I choose, however, not to include either $\mathrm{p}_{t-1}$ or $s_{t-1}$ in the policy rule for two reasons. First, this paper chiefly deals with the behavior of variables such as $s_{t+1}^{-s}$ which are unaffected by arbitrary constants added 
to s. Second, conditional variances, which also play an important role in this paper and are of the form $E_{t}\left(s_{t+1}-E_{t} s_{t+1}\right)^{2}$, are independent of any feedback from $p_{t-1}$ or $s_{t-1}$ to $m_{t}$. It therefore seems simpler to just ignore such feedback.

The general class of policy rules which are considered in this paper take the form

$$
m_{t}=\mu_{0}+\mu_{1} m_{t-1}+\mu_{2} \varepsilon_{t}+\mu_{3} u_{t}+v_{t}
$$

where $\mu_{i}$ 's are policy parameters, $-1<\mu_{1}<1$, and $v_{t}$ is a mean zero, random disturbance term.

The information structure of the model requires some comment in light of the assumption in (4) that $\mathrm{m}_{t}$ can respond to contemporaneous values of the aggregate supply and demand disturbances, $\varepsilon_{t}$ and $u_{t} \cdot$ The sequence in which information is revealed and decisions are made is as follows. At the end of period $t-1$, wage contracts applicable to period $t$ are written. Wages are based upon expectations of all variables dated $t-1$ or earlier. Next, $\varepsilon_{t}$ and $u_{t}$, the shocks to aggregate supply and demand are revealed. On the basis of the realized values of $\varepsilon_{t}$ and $u_{t}$ the monetary authority adjusts its policy variable (i.e., $\mu_{0}+\mu_{1} m_{t-1}+\mu_{2} \varepsilon_{t}+\mu_{3} u_{t}$ is determined). Then, $v_{t}$ is observed, but the monetary authority is not allowed to react to it. This shock represents, from the policymaker's point of view, uncontrollable random noise in the policy rule. The private sector, however, observes $\varepsilon_{t}$, $u_{t}$, and $v_{t}$ before taking any action during period $t$. On the basis of the observed contemporaneous shocks, expectations about variables at $t+1$ are formed. Individuals then allocate their portfolios between bonds and money and 
determine aggregate demand.

This particular information structure is not crucial for the role of monetary policy which will be discussed in this paper. Alternative monetary policy rules will lead to shifts in the portfolio balance equation and thus in the behavior of bond prices as long as 1) asset demands depend upon the distribution of $s_{t+1}$ and $p_{t+1}$ and 2) $m_{t+1}$ depends upon some variable which is unobserved at the time the portfolio choice is made. The disturbances $\varepsilon_{t+1}, u_{t+1}$, and $v_{t+1}$ are all such variables under the information structure assumed in the paper. If $\varepsilon_{t}, u_{t}$, and $v_{t}$ are not observed when the portfolio allocation is made, then letting $\mathrm{m}_{t+1}$ depend upon $\varepsilon_{t}$, $u_{t}$, and $v_{t}$ will produce results similar to those of this paper. Because individuals pay $s_{t}$ when they purchase bonds, and hence observe at least one piece of current information, it seemed unreasonable to assume they incorporate no current information into their forecasts of $s_{t+1}$ and $p_{t+1}$. One could assume that information on $\varepsilon_{t}$, $u_{t}$, and $v_{t}$ is obtained only through observing $s_{t}$ and therefore the realized values of these disturbances must be estimated on the basis of the observed value of $s_{t}$. This, however, leads to severe nonlinearities in solving for the equilibrium solution (see Barro [1980]). The information structure that is used in this paper is thus a compromise; it allows perhaps for too much current information to be available in predicting future prices, but it leads to a relatively simple solution.

Because aggregate supply depends upon $\mathrm{P}_{t}{ }_{t-1} \mathrm{P}_{t}$ and monetary policy can react to $\varepsilon_{t}$, and $u_{t}$, systematic monetary policy will have real effects; the distribution of $y_{t}$ will depend upon $\mu_{2}$ and $\mu_{3}$ in (4). Such effects, however, last for only one period. 
In later sections of this paper, equilibrium solutions for alternative policy rules will be compared where alternative policy rules are taken to mean alternative values for the parameters $\mu_{0}, \ldots, \mu_{3}$. In particular, two alternatives will generally be considered. In the first, $\mu_{0}, \mu_{1}, \mu_{2}$, and $\mu_{3}$ are nonzero and chosen to minimize bond price fluctuations. Such a policy will often be referred to as an interest rate policy. A money supply policy, on the other hand, will be one in which $\mu_{0}$ and $\mu_{1}$ are nonzero and $\mu_{2}=\mu_{3}=0$. The resulting policy rule, $\mathrm{m}_{t}=\mu_{0}+\mu_{1} \mathrm{~m}_{t-1}+\mathrm{v}_{t}$, can be interpreted as representing a policy in which the monetary authority has a desired target value, m*, for $m$ and adjusts toward $m *$ with speed given by $1-\mu_{1}$ :

$$
m_{t}-m_{t-1}=\left(1-\mu_{1}\right)\left(m *-m_{t-1}\right)+v_{t}
$$

where $m^{*}=\mu_{0} /\left(1-\mu_{1}\right)$ is a constant. Similarly, the interest rate policy can be written in the same form as (5) with the target $m^{*}$ equal to $\left(\mu_{0}+\mu_{2} \varepsilon_{t}+\mu_{3} u_{t}\right) /$ $\left(1-\mu_{1}\right)$. In this case, $m^{*}$ is adjusted in response to the observed supply and demand shocks.

These definitions of what will be called an interest rate and a money supply policy differ somewhat from standard usage, particularly the interest rate policy. Usually these alternative policies would be defined in terms of fixing either (in this model) $s_{t}$ or $m_{t}$. A fixed $s_{t}$ versus a fixed $m_{t}$ does not, however, seem to be a very interesting choice to consider in examining the effects of the Federal Reserve's October 1979 policy shift. It would seem more germane to study policies in which the monetary authority varies in the extent to which it attempts to reduce fluctuations in either $\mathrm{s}$ or $\mathrm{m}$. In what is here labeled as an interest rate policy, the monetary authority 
"worries" about bond price volatility, with the money supply rule it "worries" about volatility in the portfolio composition variable.

There is, in this model, an additional reason for not treating a fixed $\mathbf{s}$ as one alternative policy. In section $\mathrm{V}$ the portfolio balance equation (3) is derived from an underlying model of portfolio choice. It is shown that the parameters $\gamma_{0}, \gamma_{1}$, and $\gamma_{2}$ are functions of the variance of $s$. If this variance is zero, these parameters will be undefined. If bonds and money are only subject to identical price level uncertainty and their yields are not equal, only one asset will be held. A non-degenerate solution to the portfollo choice problem of section $V$ requires that $s$ be stochastic with a nonzero variance.

There is, of course, no presumption that either of these alternative policies are in any sense optimal. Given the structure of the model, the parameters of the policy rule affect the variance of output. Since the minimization of this variance is a conventional objective in analyzing policy, the values of $\mu_{0}, \ldots, \mu_{3}$ could be chosen to achieve this goal. Since the focus here is only on how the variance of bond prices might be affected by a change in policy, the issue of optimal policy will not be addressed.

To complete the actual specification of the model, the joint distribution of the disturbance terms must be defined. It will be assumed that $\varepsilon_{t}$, $u_{t}$, and $v_{t}$ are each independent normal variates with means equal to zero and variances $\sigma_{\varepsilon}^{2}, \sigma_{\mathrm{u}}^{2}$, and $\sigma_{\mathrm{v}}^{2}$, respectively. Covariances among the three disturbances are all zero and each is serially independent. We now turn to the solution of the basic linear model. 
III. The Solution for the Linear Model

The model consisting of equations (1) - (4) will be solved by the method of undetermined coefficients. A trial solution is first hypothesized for $s_{t}$ and $p_{t}$. This is then used to eliminate the expectational variables appearing in (I) - (3) under the assumption of rational expectations. Solving then for $s_{t}$ and $p_{t}$ yields functions identical in form to the initial trial solution; equating coefficients in the two expressions for the endogenous prices produces values for the coefficients in the trial solution in terms of the basic parameters of the model.

Trial solutions are given in equations (6) and (7):

$$
\begin{aligned}
& p_{t}=a_{t}+a_{1} m_{t-1}+a_{2} \varepsilon_{t}+a_{3} u_{t}+a_{4} v_{t} ; \\
& s_{t}=b_{t}+b_{1} m_{t-1}+b_{2} \varepsilon_{t}+b_{3} u_{t}+b_{4} v_{t} ;
\end{aligned}
$$

where $a_{t}, b_{t}$ are functions of time only and $a_{1}, \ldots, a_{4}, b_{1}, \ldots, b_{4}$ are, as yet, undetermined coefficients. Recalling the discussion of the previous section, arbitrary constants $a_{0}, b_{0}$ can be added to (6) and (7) without affecting the equilibrium. For the reasons discussed in the previous section, this problem of the indeterminancy of the absolute levels of $s_{t}$ and $p_{t}$ will be ignored in the remainder of the paper.

Eliminating $y_{t}$ and $m_{t}$ from (1) - (4) results in the following two equations for $p_{t}$ and $s_{t}$ :

$$
\begin{aligned}
& \alpha\left(p_{t}-{ }_{t-1} p_{t}\right)=k-\bar{y}+\beta\left({ }_{t} s_{t+1}-s_{t}\right)-\beta\left({ }_{t} p_{t+1}-p_{t}\right)+u_{t}-\varepsilon_{t} \\
& \mu_{0}+\mu_{1} m_{t-1}+\mu_{2} \varepsilon_{t}+\mu_{3} u_{t}+v_{t}=\gamma_{0}+\gamma_{1} \bar{y}+\gamma_{1} \alpha\left(p_{t}-{ }_{t-1} p_{t}\right)
\end{aligned}
$$




$$
\begin{aligned}
& -14- \\
& +\gamma_{2}\left(s_{t+1}-s_{t}\right)+\gamma_{1} \varepsilon_{t} .
\end{aligned}
$$

Terms involving expectations can be substituted out of (8) and (9) by using (6) and (7) to conclude that

$$
\begin{aligned}
& p_{t}-{ }_{t-1} p_{t}=a_{2} \varepsilon_{t}+a_{3} u_{t}+a_{4} v_{t} \\
& s_{t}-{ }_{t-1} s_{t}=b_{2} \varepsilon_{t}+b_{3} u_{t}+b_{4} v_{t} \\
& t^{p_{t+1}}=a_{t+1}+a_{1} m_{t} \\
& t^{s}{ }_{t+1}=b_{t+1}+b_{1} m_{t} .
\end{aligned}
$$

Using (4) to eliminate $\mathfrak{m}_{t}$ in these last two expressions and then substituting them all into (8) and (9) yields, when solved for $p_{t}$ and $s_{t}$, expressions for these two variables which are of the same form as (6) and (7). Equating the coefficients in these derived expressions for $p_{t}$ and $s_{t}$ with the coefficients in the trial solutions yields the following values for the parameters in (6), the solution for $p_{t}$ :

$$
\begin{aligned}
& a_{1}=-\mu_{1} /\left(1-\mu_{1}\right) \gamma_{2} \\
& a_{2}=\left[\beta\left(\frac{\mu_{2}}{1-\mu_{1}}-\gamma_{1}\right)-\gamma_{2}\right] / \gamma_{2} \mathrm{~h} \\
& a_{3}=\left[\beta \frac{\mu_{3}}{1-\mu_{1}}+\gamma_{2}\right] / \gamma_{2} \mathrm{~h} \\
& a_{4}=\beta\left(\frac{1}{1-\mu_{1}}\right) / \gamma_{2} \mathrm{~h}
\end{aligned}
$$

where $h=\alpha-\beta+\gamma_{1}^{\alpha \beta / \gamma_{2}}>0$. In addition,

$$
a_{t+1}-a_{t}=(k-\bar{y}) / \beta-\left(\gamma_{0}+\gamma_{1} \bar{y}-\frac{\mu_{0}}{1-\mu_{1}}\right) / \gamma_{2} \cdot \cdot \frac{6}{}
$$


Using these results, the equilibrium price level is given by

$$
\begin{aligned}
p_{t}=a_{t}-\frac{\mu_{1}}{\left(1-\mu_{1}\right) \gamma_{2}} m_{t-1} & +\frac{\beta}{\left(1-\mu_{1}\right) \gamma_{2} h}\left(m_{t}-{ }_{t-1} m_{t}\right) \\
& -\left(1+\beta \gamma_{1} / \gamma_{2}\right)(1 / h) \varepsilon_{t}+(1 / h) u_{t}
\end{aligned}
$$

where $m_{t}{ }_{t-1} m_{t}=\mu_{2} \varepsilon_{t}+\mu_{3} u_{t}+v_{t}$ is the unanticipated (as of $t-1$ ) component of $\mathrm{m}_{t^{*}}$ Properties of this solution will be discussed in the next section; equation (11) is simply stated here for later reference.

The parameters for the equilibrium solution for the price of bonds are given by

$$
\begin{aligned}
b_{1} & =-\mu_{1} /\left(1-\mu_{1}\right) \gamma_{2} \\
b_{2} & =\left[\frac{(\beta-\alpha) \mu_{2}}{1-\mu_{1}}-\gamma_{1} \beta\right]\left(1 / \gamma_{2} h\right) \\
b_{3} & =\left[\frac{(\beta-\alpha) \mu_{3}}{1-\mu_{1}}+\gamma_{1} \alpha\right]\left(1 / \gamma_{2} h\right) \\
b_{4} & =\frac{(\beta-\alpha)}{1-\mu_{1}}\left(1 / \gamma_{2} h\right) \\
b_{t+1}-b_{t} & =-\left(\gamma_{0}+\gamma_{1} \bar{y}-\frac{\mu_{0}}{1-\mu_{1}}\right) / \gamma_{2}
\end{aligned}
$$

These results imply that the equilibrium nominal price of bonds can be written as

$$
s_{t}=b_{t}-\frac{\mu_{1}}{\left(1-\mu_{1}\right) \gamma_{2}} m_{t-1}+\frac{(\beta-\alpha)}{\left(1-\mu_{1}\right) \gamma_{2} h}\left(m_{t}-{ }_{t-1} m_{t}\right)-\frac{\gamma_{1}}{\gamma_{2} h}\left(\beta \varepsilon_{t}-\alpha u_{t}\right)
$$


Equations (11) and (13) completely characterize the rational expectations equilibrium for this model. The results of this section can now be used to examine the properties of the equilibrium. 


\section{Properties of the Linear Model}

While the main focus of this paper is on the behavior of bond prices as a function of the policy rule followed by the monetary authority, it will be useful to begin a discussion of the model's properties by examining the equilibrium solutions for the two real variables of the model, the real rate of return on bonds and the level of output.

The ex-post real return on bonds is defined as $\left(s_{t+1}-p_{t+1}\right)-\left(s_{t}-p_{t}\right)$ $\equiv r_{t+1}$ Using the solution equations. (6) and (7) and the fact that $a_{1}=b_{1}$,

$$
\begin{aligned}
r_{t+1}=\left(b_{t+1}-b_{t}\right) & -\left(a_{t+1}-a_{t}\right)+\left(b_{2}-a_{2}\right)\left(\varepsilon_{t+1}-\varepsilon_{t}\right) \\
& +\left(b_{3}-a_{3}\right)\left(u_{t+1}-u_{t}\right)+\left(b_{4}-a_{4}\right)\left(v_{t+1}-v_{t}\right) .
\end{aligned}
$$

The equality of $a_{1}$ and $b_{1}$ in the equilibrium solution implies that the real rate of return is independent of current or past realizations of $m_{t} \cdot$ The reason for this is easy to see. Suppose all disturbances are set equal to zero. Then, from the aggregate supply relationship, $y=\bar{y}$. With output determined, the aggregate demand relationship determines the real rate of return; the current value of $m_{t}$ only affects the division of $r_{t+1}$ between the capital gain on bonds $\left(s_{t+1}-s_{t}\right)$ and the inflation return $-\left(p_{t+1}-p_{t}\right)$.

From (14), the unconditional expectation of the real interest rate, Er $t+1$, is equal to $\left(b_{t+1}-b_{t}\right)-\left(a_{t+1}-a_{t}\right)$, which, using (10e) and (12e) implies that $\operatorname{Er}_{t+1}=(\bar{y}-k) / \beta$. This is independent of the policy rule.

The solution for real output can be found by using (10b) - (10d) to evaluate the price level forecast error and substituting the result into the aggregate supply equation (1): 


$$
\begin{aligned}
y_{t}=\bar{y} & -\left(\alpha / \gamma_{2} h\right)\left(\gamma_{2}+\beta\left(\gamma_{1}-\frac{\mu_{2}}{1-\mu_{1}}\right)\right) \varepsilon_{t} \\
& +\left(\alpha / \gamma_{2} h\right)\left(\gamma_{2}+\beta \mu_{3} /\left(1-\mu_{1}\right)\right) u_{t} \\
& +\left(\alpha / \gamma_{2} h\right)\left(\beta /\left(1-\mu_{1}\right)\right) v_{t}+\varepsilon_{t} \\
=\bar{y} & +\left(\alpha \beta /\left(1-\mu_{1}\right) \gamma_{2} h\right)\left(m_{t}-{ }_{t-1} m_{t}\right)-(1 / h)\left(\beta \varepsilon_{t}-\alpha u_{t}\right)
\end{aligned}
$$

Because of the specification of the aggregate supply function, $y_{t}-\bar{y}$ is serially uncorrelated, unlike $\mathbf{r}_{t}$. Each of the coefficients on the disturbance terms in (15) are functions of the policy rule parameters so that the monetary authority can affect the variance of $y_{t}$ around $\bar{y}$ by its choice of $\mu_{1}, \mu_{2}$, and $\mu_{3}$. The results of section VI below suggest, however, that choosing the policy parameters to minimize $E\left(y_{t}-\bar{y}\right)^{2}$ as derived from (15) will not, in fact, minimize the variance of output.

The equilibrium solution for the price of bonds has already been given in equation (13). As would be expected, an unanticipated increase in $m_{t}$ due to the random policy rule shock, $v_{t}$, produces a rise in nominal bond prices $\left((\beta-\alpha) /\left(1-\mu_{1}\right) \gamma_{2} h>0\right)$. For a given money surprise, $m_{t}-{ }_{t-1} m_{t}$, positive values of the composite disturbance $\left(\beta \varepsilon_{t}-\alpha u_{t}\right)$ will increase bond prices. Since $\alpha>0, \beta<0$, positive supply or positive demand shocks both reduce current bond prices. The net effects of both $\varepsilon_{t}$ and $u_{t}$ depend upon the induced effect each has on $m_{t}{ }_{t-1} \mathfrak{m}_{t}$ via the policy rule. Even though positive realizations of both types of shocks tend, for a fixed $m_{t}{ }_{t-1} m_{t}$, to reduce nominal bond prices, an examination of equation (14) shows that positive supply shocks reduce, and demand shocks increase, the expected real return on bonds $t^{r}{ }_{t+1}$. 
There are two alternative ways in which one could define bond price volatility, corresponding to the variance of $s_{t}$ conditional on information available at time $t-1$ or the unconditional variance of $s_{t}$. This latter measure is obtained by replacing $m_{t-1}$ in the solution for $s_{t}$ by $\mu_{0} /\left(1-\mu_{1}\right)$ $+\sum_{1}^{\infty} \mu_{1}^{i-1}\left(\mu_{2} \varepsilon_{t-i}+\mu_{3} u_{t-i}+v_{t-i}\right)$. Making this substitution yields

$$
\begin{aligned}
s_{t}=b_{t} & +b_{1} \mu_{0} /\left(1-\mu_{1}\right)+\left(b_{2}+\mu_{2} b_{1} \sum \mu_{1}^{i-1} L^{i}\right) \varepsilon_{t} \\
& +\left(b_{3}+\mu_{3} b_{1} \Sigma \mu_{1}^{i-1} L^{i}\right) u_{t}+\left(b_{4}+b_{1} \sum \mu_{1}^{i-1}{ }_{L}^{i}\right) v_{t}
\end{aligned}
$$

where $L$ is the lag operator (i.e., $L^{i} v_{t}=v_{t-i}$ ). This expression can then be used to calculate the unconditional variance $E\left(s_{t}-E s_{t}\right)^{2}$ which would yield a measure of the gross volatility of bond prices. $\stackrel{7 /}{ }$ Generally, however, the conditional variance of $s$ will be used in this paper as a measure of volatility. $8 /$ This is given by

$$
\sigma_{s}^{2}=E_{t-1}\left(s_{t}-E_{t-1} s_{t}\right)^{2}=b_{2}^{2} \sigma_{\varepsilon}^{2}+b_{3}^{2} \sigma_{u}^{2}+b_{4}^{2} \sigma_{v}^{2}
$$

which, using the results in (12), is equal to

$$
\begin{aligned}
\sigma_{S}^{2}=\left(1 / \gamma_{2}^{2} h^{2}\right) & {\left[\left(\mu_{2}(\beta-\alpha) /\left(1-\mu_{1}\right)-\gamma_{1} \beta\right)^{2} \sigma_{\varepsilon}^{2}+\left(\mu_{3}(\beta-\alpha) /\left(1-\mu_{1}\right)\right.\right.} \\
& \left.\left.+\gamma_{1} \alpha\right)^{2} \sigma_{u}^{2}+\left((\beta-\alpha) /\left(1-\mu_{1}\right)\right)^{2} \sigma_{v}^{2}\right] .
\end{aligned}
$$

Suppose the monetary authority adopts an interest rate oriented policy. in which it reacts to supply and demand shocks in an attempt to stabilize bond prices. From (18), it appears that by an appropriate choice of $\mu_{2}$ and $\mu_{3}$, nominal bond prices can be completely insulated from variations due to $\varepsilon$ 
or $u$. The required values for the policy parameters are $\mu_{2} /\left(1-\mu_{1}\right)$ $=\gamma_{1} \beta /(\beta-\alpha)>0$ and $\mu_{3} /\left(1-\mu_{1}\right)=-\gamma_{1} \alpha /(\beta-\alpha)>0$. Interpreting the policy rule as adjusting $m$ to $\mathrm{m}^{*}$ as in (5), $\mathrm{m}^{*}$ responds positively to both supply shocks and demand shocks in order to minimize fluctuations in s. Since positive realizations of either $\varepsilon_{t}$ or $u_{t}$ lead to higher income and a greater demand for money, both will tend to depress bond prices. To offset this effect and stabilize $s$ requires an expansionary monetary policy; $\mathrm{m}^{*}$ is increased. The resulting variance of bond prices, for a given adjustment speed $1-\mu_{1}$, is

$$
\sigma_{\mathrm{S} / \mathrm{s}}^{2}=\frac{(\beta-\alpha)^{2}}{\left(1-\mu_{1}\right)^{2} \gamma_{2}^{2} \mathrm{~h}^{2}} \sigma_{\mathrm{v}}^{2}
$$

where the new subscript on $\sigma_{s}^{2}$ indicates that this is the variance of $s$ under a policy which picks $\mu_{2}$ and $\mu_{3}$ to minimize $\sigma_{s}^{2}$. It will be shown in section VI, however, that this policy does not, in fact, minimize $\sigma_{S}^{2}$ for a given $\mu_{1} \cdot \underline{9}$

Instead of attempting to stabilize bond prices, suppose that $\mathrm{m}^{*}$ is not adjusted in light of the realized values of $\varepsilon_{t}$ and $u_{t}\left(\mu_{2}=\mu_{3}=0\right)$. In this case, $m$ is adjusted toward a constant target at the rate $1-\mu_{1}$. Equation (18) then implies that

$$
\sigma_{\mathrm{S} / \mathrm{m}}^{2}=\frac{\gamma_{I}^{2}}{\gamma_{2}^{2} \mathrm{~h}^{2}}\left(\beta^{2} \sigma_{\varepsilon}^{2}+\alpha^{2} \sigma_{\mathrm{u}}^{2}\right)+\frac{(\beta-\alpha)^{2}}{\left(1-\mu_{1}\right)^{2} \gamma_{2}^{2} \mathrm{~h}^{2}} \sigma_{\mathrm{v}}^{2}
$$

A comparison of (19) and (20) reveals that for equal values of the adjustment parameter $\mu_{1}$, 


$$
\sigma_{s / \mathfrak{m}}^{2}-\sigma_{s / s}^{S}=\left(\gamma_{1} / \gamma_{2} h\right)^{2}\left(\beta^{2} \sigma_{\varepsilon}^{2}+\alpha^{2} \sigma_{u}^{2}\right) \equiv c_{0}>0
$$

Within the framework of this model, a shift to a monetary aggregates policy increases the variance of $s$, a trivial result since the alternative had been chosen to minimize $\sigma_{s}^{2}$. However, equation (21) defining $c_{0}$ will be used later in determining the extent to which $\sigma_{s}^{2} /$ m in (20) may actually understate the variance of $s$ when $\mu_{2}=\mu_{3}=0$.

The model specified in (1) - (3) is ad hoc, chosen for its plausibility and the ease with which it can be manipulated rather than as the implication of a model based upon individual maximizing behavior. In particular, the portfolio balance equation (3) corresponds to what Bryant and Wallace [1980] have labeled the "starting from curves approach." In the next section, it will be shown how (3) can be derived from an underlying model of portfolio choice. This derivation suggests that the parameters of the portfolio balance equation, $\left(\gamma_{0}, \gamma_{1}, \gamma_{2}\right)$, will not be policy invariant. Subsequent sections discuss the implications of this result. 


\section{The Portfolio Choice Model}

The results of the previous section imply that both the rate of inflation and the rate of interest (capital gains on bonds) are stochastic variables. The real return from holding either money or bonds is thus subject to risk. Models of portfolio choice (e.g., Tobin [1958]) suggest that this risk is important in determining the demand for assets. One would expect, then, that the condition for portfolio balance, equation (3) in the model of sections II - IV, should depend upon the risk characteristics of bonds and money. It is this dependency that will be examined in this section.

Throughout, it will be assumed that all individuals are identical. This fiction allows the portfolio choice problem to be formulated in terms of a representative individual. It is also assumed that the representative individual exhibits constant relative risk aversion. This implies that the optimal portfolio composition is independent of the level of wealth. Such an assumption will be necessary if an equation such as (3) is to be derived since (3) focuses on the equilibrium fraction of wealth held in the form of money.

The solution equations derived in section 3 showed that both bond prices and the price level were linear functions of normally distributed random variables. Therefore $s$ and $p$ were themselves normally distributed. In this case the returns to holding bonds and money are completely characterized by their means, variances, and covariances. Assume then that the risk averse representative individual's expected utility can be written as a linear function of the mean and variance of his or her 
portfolio's real rate of return, $r_{p}$ :

$$
U=t_{p t+1}^{r}-(1 / 2) \rho E_{t}\left(r_{p t+1}-t^{r} p t+1\right)^{2}
$$

The return on the portfolio is defined as $r_{p t+1}=r_{m t+1} m_{t}+r_{b t+1}\left(1-m_{t}\right)$ where $r_{m}$ and $r_{b}$ are the real rates of return on money and bonds, respectively, and $m_{t}$ is the fraction of wealth held in the form of money. In previous sections, $r_{b t+1}$ has been approximated by $\left(s_{t+1}-p_{t+1}\right)-\left(s_{t}-p_{t}\right)$. The real return to money will be assumed to consist of two components: a return to the transaction services yielded by money and a capital gains return resulting from price level changes:

$$
r_{m t+1}=\tau y_{t}-\left(p_{t+1}-p_{t}\right)
$$

where, for simplicity, the transactions return is taken to be proportional to real output. One could think of $\tau$ as a function of the variance of individual expenditures within each period. (See Santomero and Seater [1981].)

By rearranging the first order condition for the maximization of (22) with respect to $m_{t}, \frac{10 /}{2}$ and defining $\sigma_{s p}=E_{t}\left(s_{t+1}-E_{t} s_{t+1}\right)\left(p_{t+1}-E_{t} P_{t+1}\right)$, the following relationship can be derived:

$$
m_{t}=\left(1-\frac{\sigma p}{\sigma_{s}^{2}}\right)+\frac{\tau}{\rho \sigma_{s}^{2}} y_{t}-\frac{1}{\rho \sigma_{s}^{2}}\left(t_{t+1}{ }^{-s_{t}}\right)
$$

Equation (24) is of exactly the same form as the original portfolio balance relationship given by equation (3). However, equation (24) allows a structural interpretation to be given to the parameters of equation (3). 
Comparing the two equations reveals that $\gamma_{0}=1-\sigma_{s p} / \sigma_{s}^{2}, \gamma_{1}=\tau / \rho \sigma_{s}^{2}$, and $\gamma_{2}=-1 / \rho \sigma_{s}^{2}$

If a requirement for a rational expectations equilibrium is that the distribution of asset returns implied by the model be identical to the distribution upon which asset demands are based, then the value of $\sigma_{s}^{2}$ which appears in (24) must equal the value of $\sigma_{S}^{2}$ predicted by the model. This condition imposes nonlinear restrictions on the model since equation (24) implies that $\gamma_{2}$ is a function of $\sigma_{s}^{2}$ while equation (18) implies that $\sigma_{s}^{2}$ is a function of $\gamma_{2}^{2}$.

The implications of this additional restriction are developed in the next two sections, but one conclusion is immediate. In the previous section two alternative policies were considered. Each policy led to a different variance of bond prices $\left(\sigma_{\mathrm{s}}^{2} / \mathrm{s}\right.$ in equation (19) and $\sigma_{\mathrm{s} / \mathrm{m}}^{2}$ in equation (20)). In comparing these two variances, however, $\gamma_{1}$ and $\gamma_{2}$ were treated as fixed parameters which remained unchanged as $\sigma_{s}^{2}$ changed. The results of this section show that this was not a valid assumption. It is necessary to redo the comparison, taking into account the changes in $\gamma_{1}$ and $\gamma_{2}$ induced by the policy shift. 
VI. Equilibrium in the Non-Linear Model

Sections III and IV showed how the actual distribution of bond prices is a function of the parameters of the portfolio balance equation. Section $V$ showed how the parameters of the portfolio balance equation are functions of investors' (homogeneous) beliefs about the distribution of bond prices. In a rational expectations equilibrium, the subjective distribution upon which $\gamma_{0}, \gamma_{1}$, and $\gamma_{2}$ are based must equal the actual distribution determined by $\gamma_{0}, \gamma_{1}$, and $\gamma_{2}$ via the assumption of market clearing.

In deriving the solution in section III, only the means of the actual and the subjective distribution of $s$ were required to be equal. The requirement that the variances also be equal implies that $\gamma_{2}$ and $\sigma_{s}^{2}$ are linked by two relationships. With $\gamma_{1}=\tau / \rho \sigma_{s}^{2}$ and $\gamma_{1} / \gamma_{2}=-\tau$, equation (18) becomes,

$$
\begin{gathered}
\sigma_{S}^{2}=\frac{\tau^{2}}{h^{2}}\left(\beta^{2} \sigma_{\varepsilon}^{2}+\alpha^{2} \sigma_{u}^{2}\right)+\frac{2(\beta-\alpha)}{\left(1-\mu_{1}\right)} \frac{\left(\beta \mu_{2} \sigma_{\varepsilon}^{2}-\alpha \mu_{3} \sigma_{u}^{2}\right) \tau}{h^{2}}\left[\frac{1}{\gamma_{2}}\right] \\
+\frac{(\beta-\alpha)^{2}}{\left(1-\mu_{1}\right)^{2}} \frac{\left(\mu_{2}^{2} \sigma_{\varepsilon}^{2}+\mu_{3}^{2} \sigma_{u}^{2}+\sigma_{v}^{2}\right)}{h^{2}}\left[\frac{1}{\gamma_{2}^{2}}\right] \\
=c_{0}+c_{1}\left[\frac{1}{\gamma_{2}}\right]+c_{2}\left[\frac{1}{\gamma_{2}}\right]^{2}
\end{gathered}
$$

where $h=\alpha-\beta-\tau \alpha \beta$. From (24),

$$
\gamma_{2}=-1 / \rho \sigma_{s}^{2}
$$


Using the results of section $V$, the equilibrium functions (11) and (13) for the log of the price level and the log of the bond price can be rewritten as

$$
\begin{aligned}
& p_{t}=a_{t}+\frac{\rho \sigma_{s}^{2} \mu_{1}}{\left(1-\mu_{1}\right)} m_{t-1}-\frac{\rho \sigma_{s}^{2} \beta}{\left(1-\mu_{1}\right) h}\left(m_{t}-m_{t}\right) \\
&-(1-\beta \tau)(1 / h) \varepsilon_{t}+(1 / h) u_{t} \\
& s_{t}=b_{t}+\frac{\rho \sigma_{s}^{2} \mu_{1}}{\left(1-\mu_{1}\right)} m_{t-1}-\frac{\rho \sigma_{s}^{2}(\beta-\alpha)}{\left(1-\mu_{1}\right) h}\left(m_{t}-m_{t}\right) \\
&+(\tau / h)\left(\beta \varepsilon_{t}-\alpha u_{t}\right)
\end{aligned}
$$

Equilibrium in the non-linear model is a quadruple $\left(p_{t}, s_{t}, \gamma_{2}, \sigma_{s}^{2}\right)$ which satisfies $\left(11^{\circ}\right),\left(13^{\circ}\right),(25)$, and (26). Because of the structure of the model, equations (25) and (26) can be first solved for $\gamma_{2}$ and $\sigma_{s}^{2}$. The

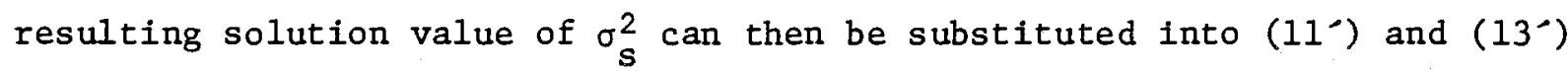
to find the equilibrium values of $p_{t}$ and $s_{t}$.

Using (26) to eliminate $\gamma_{2}$ from (25) yields the following quadratic equation in $\sigma_{S}^{2}$ :

$$
c_{2} \rho^{2} \sigma_{s}^{4}-\left(1+c_{1} \rho\right) \sigma_{s}^{2}+c_{0}=0
$$

Equation (27) admits of three possibilities, corresponding to whether there is no positive solution for $\sigma_{s}^{2}$, a unique solution, or two solutions. Which alternative is relevant depends upon the values of $c_{0}, c_{1}$, and $c_{2}$, of which $c_{1}$ and $c_{2}$ depend upon the policy parameters $\mu_{1}, \mu_{2}$, and $\mu_{3}$. Certain choices 
of the policy rule parameters can lead to a situation in which no rational expectations equilibrium exists in this model (see Walsh [1982] for a similar conclusion in an overlapping generations model).

Figure 1 graphs the two relationships between $\gamma_{2}$ and $\sigma_{s}^{2}$ that must simultaneously be satisfied in a rational expectations equilibrium. The curve PP represents equation (26): $\gamma_{2}=-1 / \rho \sigma_{\mathrm{s}}^{2}$. Curves AA, BB, and CC represent equation (25) for alternative values of $c_{1}$ and $c_{2}$. For convenience in making the comparison, $c_{0}$ is taken to be the same for each of the curves. AA has no intersection with PP: there are no $\left(\gamma_{2}, \sigma_{s}^{2}\right)$ combinations which are simultaneously consistent with the portfolio choice model and market clearing. BB leads to a unique equilibrium with $\gamma_{2}$ and $\sigma_{s}^{2}$ given by point $E_{B}$. Finally, $C C$ has two intersections with $P P$, both of which are rational expectations equilibria. At $E_{c}^{\prime}, \sigma_{S}^{2}$ is small, leading via PP to a large $\gamma_{2}$. A large $\gamma_{2}$ implies that random shocks to m require only small bond price movements to maintain money market equilibrium. Hence, bond prices are relatively stable, thus validating the large $\gamma_{2}$. The opposite story can be told about $E_{c}^{-\prime}$. For the case in which there are two solutions, only $E_{C}^{-}$, where $C C$ cuts PP from above, is a stable equilibrium; $E_{C}^{-}$is unstable. This is illustrated in Figure 2. Suppose initially that individuals believe that $\sigma_{s}^{2}<\bar{\sigma}_{s}^{2}$ so that from PP $\left|\gamma^{-}\right|>\left|\bar{\gamma}_{2}\right|$. Market clearing implies that $\gamma_{2}^{\prime}$ will lead to a variance of bond prices greater than that upon which $\gamma_{2}^{\prime}$ was based. This leads to an adjustment in $\gamma_{2}$ that moves it toward $\bar{\gamma}_{2}$. Similar reasoning shows that $\mathrm{E}^{-1}$ is unstable. Since along PP $\sigma_{S}^{2} \rightarrow 0$ as $\gamma_{2} \rightarrow-\infty$, and, along CC $\sigma^{2} \rightarrow c_{0}$ and $\gamma_{2} \rightarrow-\infty$, as long as $c_{0}>0$ if there are two equilibria, the one with the smaller $\sigma_{s}^{2}$ will be the stable equilibria. 
Suppose we now reexamine the policy that equation (18) (which ignored the dependency of $\gamma_{2}$ on $\sigma_{s}^{2}$ ) implied would minimize bond price fluctuations. This policy involved choosing $\mu_{2}$ and $\mu_{3}$ such that $b_{2}=b_{3}=0$ in the solution equation for $s$. This in turn leads to equation (25) taking the form

$$
\sigma_{s}^{2}=\frac{(\beta-\alpha)^{2}}{\left(1-\mu_{1}\right)^{2} h^{2}} \sigma_{v}^{2}\left[\frac{1}{\gamma_{2}}\right]^{2}
$$

which is just equation (19). This relationship between $\sigma_{s}^{2}$ and $\gamma_{2}$ is graphed in Figure 3 (labeled II) together with the curve PP derived from (26). At point $E, \sigma_{S}^{2}=\left(1-\mu_{1}\right)^{2} h^{2} /(\beta-\alpha)^{2} \rho^{2} \sigma_{V}^{2}$ and the slope of II $\left(2 / \rho \gamma_{2}^{2}\right)$ is greater than the slope of PP $\left(1 / \rho \gamma_{2}^{2}\right)$ so that II cuts PP from below as drawn in Figure 3. Hence, the equilibrium at $\mathrm{E}$ is unstable. The other intersection between II and PP is at $\sigma_{s}^{2}=0, \gamma_{2}=-\infty$ at which point the equilibrium is not consistent with $0<\mathrm{m}<1$.

When the dependency of $\gamma_{2}$ on $\sigma_{s}^{2}$ is ignored, the policy which attempts to minimize bond price variation is either explosive (if the economy starts out to the right of $\mathrm{E}$, that is, if initially individuals expect bond prices to be fairly volatile) or converges to an equilibrium in which the demand for money is either zero or equal to total wealth. If points at which the equilibrium is not defined for $0<m<1$ are excluded (i.e., if we exclude $\sigma_{S}^{2}=0$ ), it is clear that point $E$, the nonzero bond price variance associated with the linear model's minimum variance policy does not, in fact, minimize the variance of $\mathrm{s}$. Altemative policies, such as the one associated with the dashed curve in Figure 3 lead to stable equilibria with a variance of $s$ less than $\sigma_{s}^{2} / s^{\cdot}$ 
VII. Predicting $\sigma_{S}^{2}$ When Policy Changes

Suppose that the monetary authority has been following a policy designed to lead to relatively stable bond prices. Let the resulting relationship between $\gamma_{2}$ and $\sigma_{s}^{2}$ implied by market clearing under this policy be a locus such as AA in Figure 4.

Now suppose that the monetary authority decides to adopt a policy under which the target $\mathrm{m}^{*}$ is not adjusted in response to the realized values of either $\varepsilon$ or $u\left(\mu_{2}=\mu_{3}=0\right)$. $\frac{11 /}{}$ Using the linear model solution of section IV, this policy switch is predicted to lead to greater interest rate volatility. If the dependency of $\gamma_{2}$ on $\sigma_{s}^{2}$ is ignored, will the predicted increase in the variance of $s$ exceed or fall short of the actual increase in the variance? In other words, suppose the model in (1) - (4) is estimated using data from the policy regime under which $\bar{\sigma}_{S}^{2}$ was the variance of $\mathrm{s}$. If the resulting empirically estimated parameters are used to evaluate the new policy, suppose $\sigma_{S L}^{2} \underline{12 /}$ is predicted as the new varlance of $s$. How does $\sigma_{S L}^{2}$ compare with $\sigma_{S N}^{2}$, the actual new equilibrium variance under the aggregates policy in which $\mu_{2}=\mu_{3}=0$.

That $\sigma_{\mathrm{SL}}^{2}$ and $\sigma_{\mathrm{SN}}^{2}$ will differ is simply one example of Lucas's [1976] policy evaluation critique. The parameters of empirically estimated macroeconomic models are not policy invariant. By explicitly deriving in section $V$ the relationship between the parameters of the portfolio balance equation and the underlying stochastic structure of the model, one can say more about the relationship between $\sigma_{\text {SL }}^{2}$ and $\sigma_{\text {SN }}^{2}$ than simply that they will differ. 
Let $\bar{\gamma}_{0}, \bar{\gamma}_{1}, \bar{\gamma}_{2}$ be the estimated parameter values obtained during the previous policy regime. Estimation error will be ignored so that $\bar{\gamma}_{0}=1$ $\bar{\sigma}_{s p} / \bar{\sigma}_{s}^{2}, \bar{\gamma}_{1}=\tau / \rho \bar{\sigma}_{s}^{2}$, and $\bar{\gamma}_{2}=-1 / \rho \bar{\sigma}_{s}^{2}$ where $\bar{\sigma}_{s p}$ is the covariance between $s$ and p during the previous policy regime. From equation (18), the predicted variance of $s$ under the new policy is

$$
\begin{aligned}
\sigma_{S L}^{2} & =\frac{\bar{\gamma}_{1}^{2}}{\bar{\gamma}_{2}^{2} h^{2}}\left(\beta_{\varepsilon}^{2} \sigma_{\varepsilon}^{2}+\alpha^{2} \sigma_{u}^{2}\right)+\frac{(\beta-\alpha)^{2} \sigma_{v}^{2}}{\left(1-\mu_{1}\right)^{2} h^{2} \bar{\gamma}_{2}^{2}} \\
& =c_{0}+\frac{(\beta-\alpha)^{2} \sigma_{v}^{2}}{\left(1-\mu_{1}\right)^{2} h^{2} \bar{\gamma}_{2}^{2}}
\end{aligned}
$$

Equations (25) and (26), however, imply that the actual variance under the new policy is given by the solution to

$$
\begin{aligned}
\sigma_{s N}^{2} & =\frac{\tau^{2}}{h^{2}}\left(\beta^{2} \sigma_{\varepsilon}^{2}+\alpha^{2} \sigma_{u}^{2}\right)+\frac{(\beta-\alpha)^{2} \sigma_{V}^{2} \rho^{2} \sigma_{s N}^{4}}{\left(I-\mu_{I}\right)^{2} h^{2}} \\
& =c_{0}+\frac{(\beta-\alpha)^{2} \sigma_{v}^{2} \rho^{2} \sigma_{S N}^{4}}{\left(I-\mu_{1}\right)^{2} h^{2}}
\end{aligned}
$$

The first term in both (29) and (30) equals $c_{0}$ since $\bar{\gamma}_{1} / \bar{\gamma}_{2}=$ $\gamma_{1} / \gamma_{2}=-\tau$, and $h$ is policy invariant. Subtracting (29) from (30) yields

$$
\begin{aligned}
\left(\sigma_{S N}^{2}-\sigma_{S L}^{2}\right) & =\frac{(\beta-\alpha)^{2} \sigma_{V}^{2}}{\left(1-\mu_{1}\right)^{2} h^{2}}\left(\rho^{2} \sigma_{S N}^{4}-\frac{1}{\bar{\gamma}_{2}^{2}}\right) \\
& =\frac{(\beta-\alpha)^{2} \sigma_{V}^{2} \rho^{2}}{\left(1-\mu_{1}\right)^{2} h^{2}}\left(\sigma_{S N}^{4}-\bar{\sigma}_{S}^{4}\right)>0
\end{aligned}
$$


since $\sigma_{S N}^{2}>\bar{\sigma}_{S}^{2}$ and $(\beta-\alpha)^{2} \sigma_{v}^{2} \rho^{2} /\left(1-\mu_{1}\right)^{2} h^{2}>0$. Equation (3I) shows that a shift in policy from one which stabilizes (partially) bond prices to a monetary aggregates policy (as defined in this paper) will result in a larger increase in the variance of bond prices than would be predicted from a model estimated under the previous policy regime.

Figure 4 illustrates this result, $E_{1}$ represents the initial equilibrium. The shift to $\mu_{2}=\mu_{3}=0$ results in a new locus of $\left(\gamma_{2}, \sigma_{s}^{2}\right)$ points consistent with market equilibrium; let this locus be BB. The new rational expectations equilibrium is at $E_{2}$.

The standard approach to policy analysis treats $\gamma_{2}$ as a policy invariant parameter, equal to $\bar{\gamma}_{2}$. Given the shift from AA to BB, the variance of $s$ is predicted to rise to $\sigma_{\mathrm{SL}}^{2}$ given by $E_{3}$. This will be less than the actual rise in the variance since the induced fall in the interest elasticity of the demand for money is ignored. 


\section{Summary and Conclusions}

Previous models in the rational expectations macroeconomic literature have assumed that the parameters of the equation describing portfolio balance are policy invariant. Models of portfolio choice, however, imply that these parameters are functions of the stochastic properties of the interest rate (bond prices in this model). This leads to two relationships connecting the bond price elasticity of the demand for money and the variance of bond prices. First, the assumption of market clearing makes the variance a function of this elasticity, and, second, the elasticity is, from the portfolio choice model, a function of the variance of bond prices. Finding values which simultaneously satisfy both restrictions leads to the possibility of multiple solutions.

If monetary policy can react in the future to shocks which are not observed when individuals choose their portfolios, changes in the policy rule followed by the monetary authority will affect the stochastic properties of bond prices. Such a policy change will, therefore, also result in changes in the parameters of the portfolio balance equation. This is an example of the Lucas policy evaluation critique: we cannot assume the parameters of the portfolio balance equation remain constant under alternative policy regimes.

By linking portfolio balance to a specific model of portfolio choice, it was possible to determine how parameters such as the bond price elasticity of the demand for money depended upon the policy rule. It was shown how ignoring this dependency would lead to an underestimation of the increase in the variance of bond prices that would result from a shift to a monetary 
aggregates policy.

In focusing on the role of the policy rule in affecting the variance of bond prices, other properties of the model were not discussed. For example, the results of the papers cited in footnote 1 are called into question; attempts to design policies to minimize output fluctuations which neglect the induced shifts in asset demand equations will fail to lead to the optimal policy. 


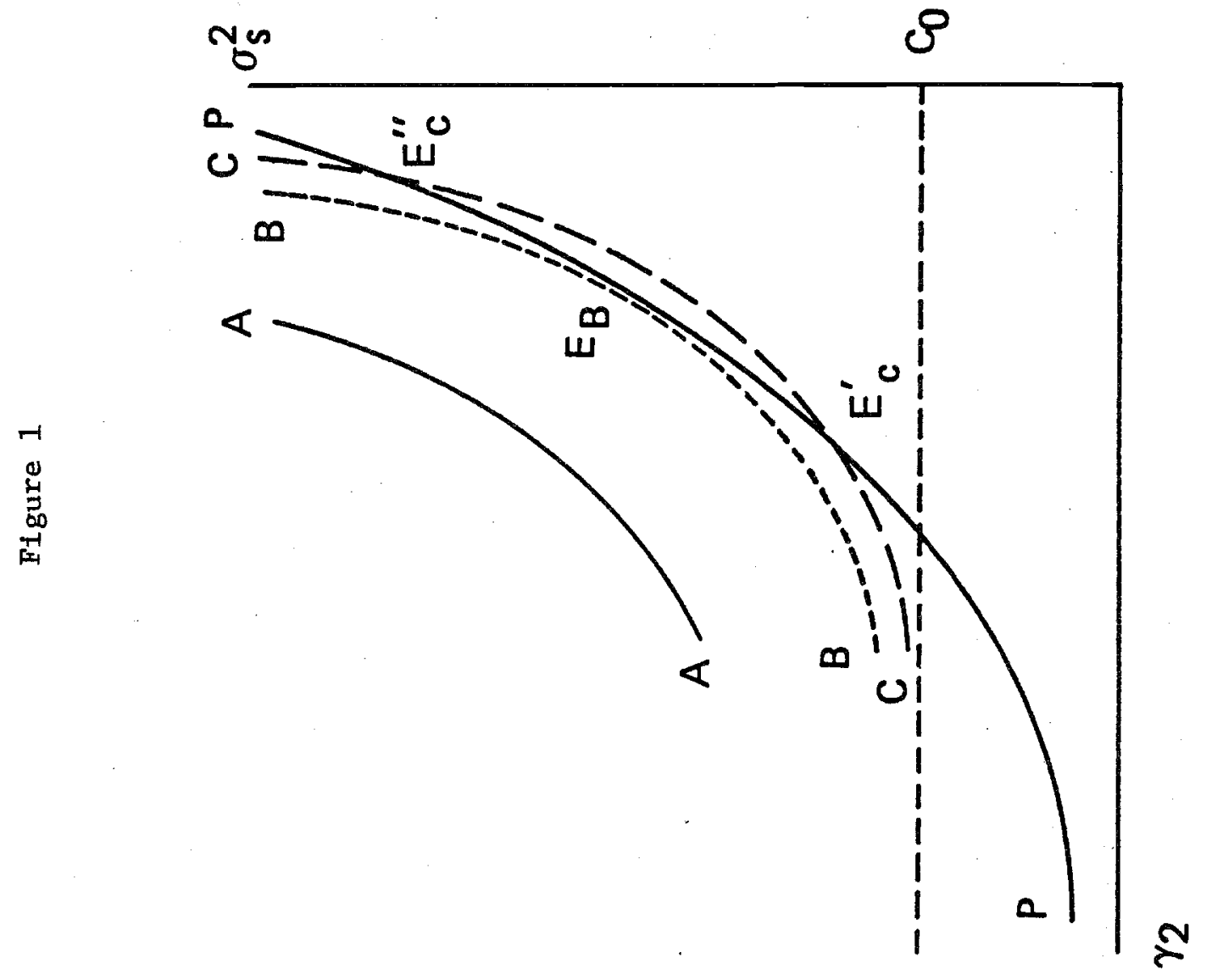




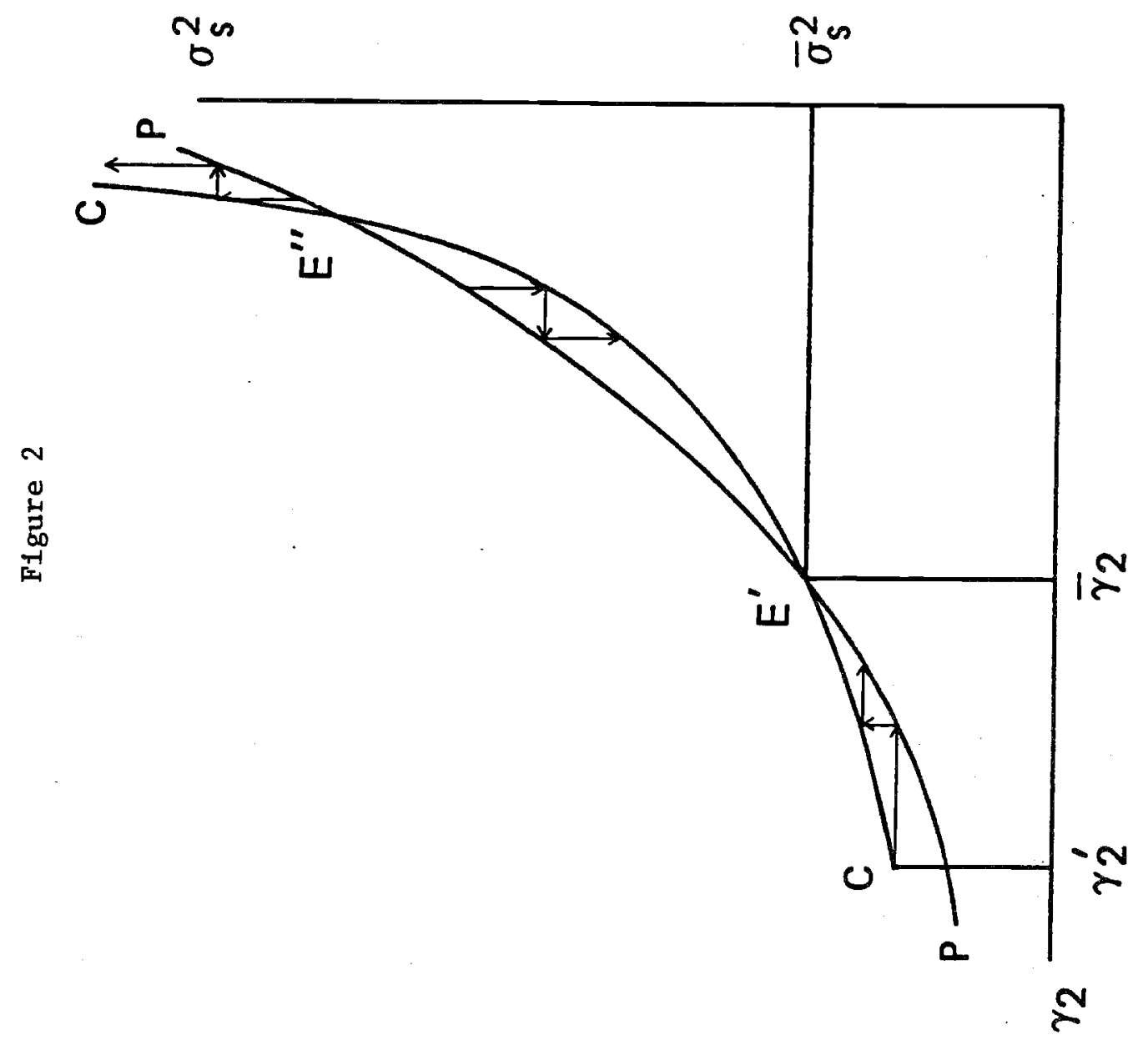




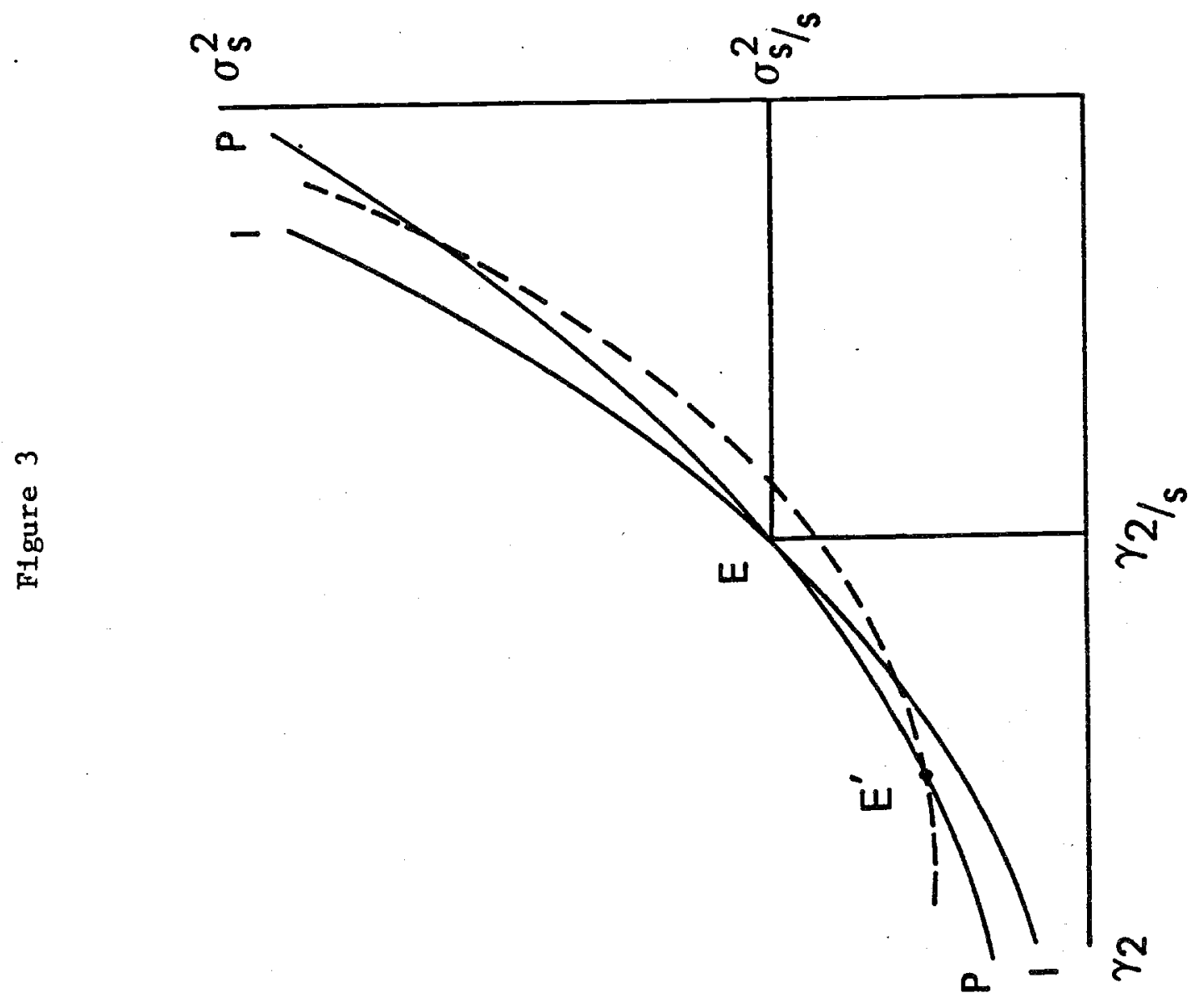




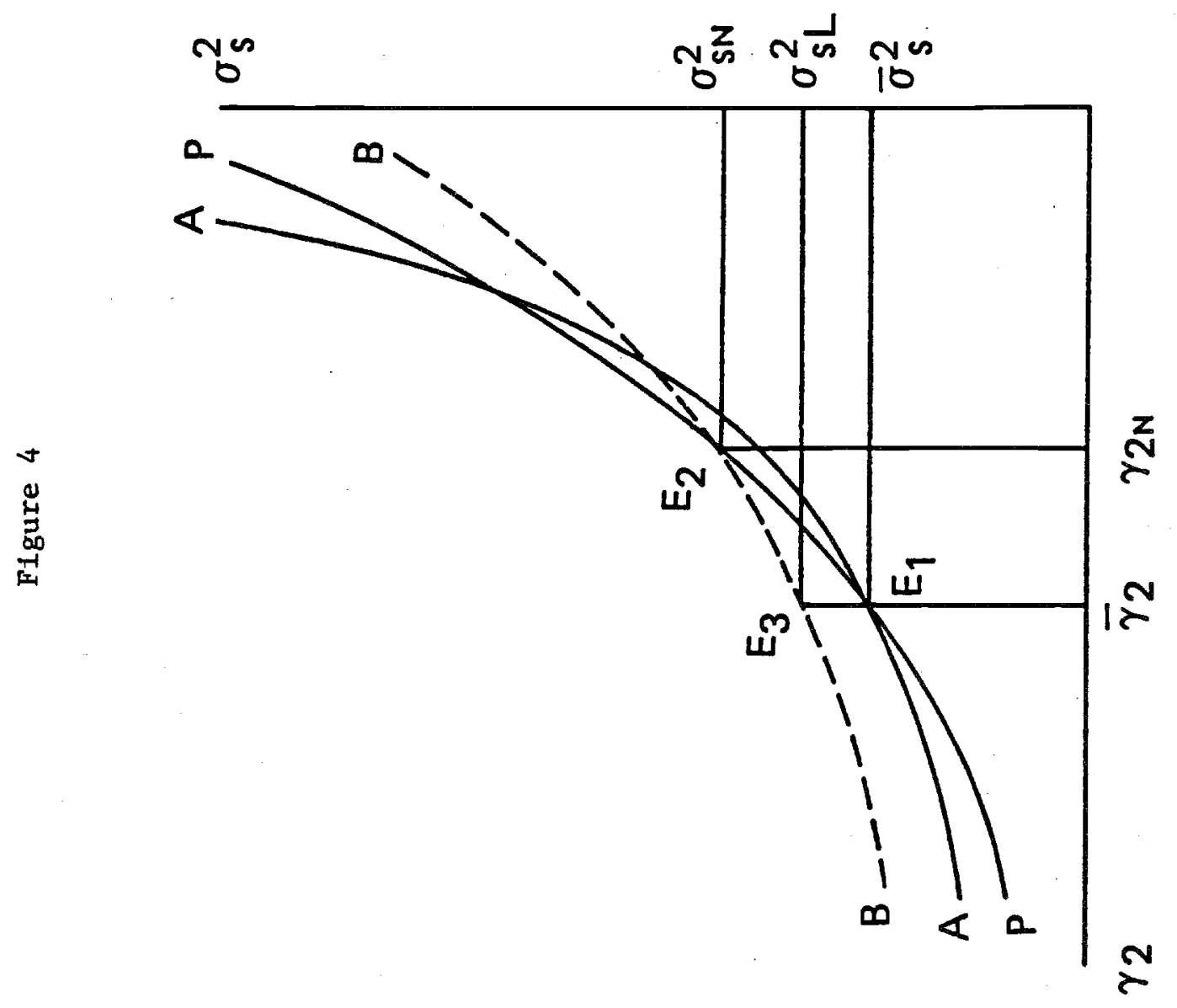




\section{Footnotes}

*Assisant Professor, Princeton University, and Visiting Scholar, Federa1 Reserve Bank of Kansas City. I would like to thank members of the research department of the Federal Reserve Bank of Kansas City for helpful comments. Any opinions expressed are those of the author and do not necessarily reflect the views of the Federal Reserve Bank of Kansas City or the Federal Reserve Sys tem.

1/ The original analysis of interest rate versus money supply policies was due to Poole [1970]. Other authors utilizing this approach include Friedman [1977], Sargent and Wallace [1975], Flood [1979], Woglom [1979], and Weber [1981]. The results of all these papers are called into question by the arguments made in this paper.

2/ Problems of uniqueness in linear rational expectations models are discussed in Taylor [1977] and Flood and Garber [1980].

3/ The minimum variance policy implied by the linear model has two solutions. One involves a positive variance for bond prices which is not a minimum (and is unstable). The other implies a zero variance (which is obviously a minimum), but, given a money demand function derived from a mean-variance framework, a nonstochastic return on bonds implies nondiversified portfolios. Since nominal interest rates appear to be stochastic, the statement in the text ignores the zero variance solution.

4/ It thus corresponds to what Bryant and Wallace [1980] describe as the "Starting from Curves" approach common in macroeconomic modeling. 5/ By definition $0 \leq m \leq 1$. It is assumed that this is never a binding constraint. 
6/ Since the model can determine rates of inflation and capital gains but not levels of $p$ and $s$, only $a_{t+1}-a_{t}$, and similarly $b_{t+1}-b_{t}$, can $b e$ determined.

I/ This measure of volatility ignores, however, the change in s due to the evolution of the deterministic part of $s$ (i.e., $b_{t}-b_{t-1}$ ).

8/ In Tinsley et al. [1981], $E_{t-I}\left(s_{t}-E_{t-I} s_{t}\right)^{2}$ is described as "a more relevant measure of undesirable interest rate volatility than the fluctuations of total changes" in bond prices.

9/ The policy which from (18) appears to minimize $\sigma_{S}^{2}$ is shown in section VI to be consistent with two equilibria: in one, $\sigma_{S}^{2}>0$ and is not a minimum; the other has $\sigma_{S}^{2}=0$ which is certainly a minimum but implies that the demand for either money or bonds is equal to zero or the optimal portfolio allocation is indeterminant. Among "well defined" equilibria, then, the policy does not minimize $\sigma_{S}^{2}$. This is discussed further in section VI.

10/ Since money and bonds in this model are both liabilities of the government, m is constrained to lie between 0 and 1 . It is assumed that this is not a binding constraint.

II/ $\mu_{1}$ is taken to remain unchanged as a result of the policy shift. 12/ The subscript $L$ denotes that this corresponds to the variance predicted by the linear model of sections III and IV. 


\section{References}

Aoki, Masanao and Matthew Canzoneri [19.79], "Reduced Forms of Rational Expectations Models," Quarterly Journal of Economics, 93, No. 1 (February), 59-71.

Barro, Robert J. [1976], "Rational Expectations and the Role of Monetary Policy," Journal of Monetary Economics, 2, No. 1 (January), 1-32. Barro, Robert.J. [1977], "Long-Term Contracting, Sticky Prices, and Monetary Policy," Journal of Monetary Economics, 3, No. 3 (July), 305-316. Barro, Robert J. [1980], "A Capital Market in an Equilibrium Business Cycle Model," Econometrica, 48, No. 6 (September), 1393-1417. Bryant, John and Neil Wallace [1980], "A Suggestion for Further Simplifying the Theory of Money," Staff Report 62, Federal Reserve Bank of Minneapolis (August).

Fair, Ray [1981], "Estimated Effects of the October 1979 Change in Monetary Policy on the 1980 Economy," American Economic Review, 71 (May), $160-165$.

Feige, Edgar L. and Robert McGee [1979.], "Has the Federal Reserve Shifted From a Policy of Interest Rate Targets to a Policy of Monetary Aggregate Targets?" Journal of Money, Credit, and Banking, 11, No. 4 (November), 381-404.

Fischer, Stanley [1977], "Long-Term Contracts, Rational Expectations and the Optimal Money Supply Rule," Journal of Political Economy, 85, No. 1 (February), 191-205.

Flood, Robert P. [1979], "Capital Mobility and the Choice of Exchange Rate System," International Economic Review, 20, No. 2 (June), 405-416. 
Flood, Robert P. and Peter M. Garber [1980], "Market Fundamentals vs. Price Level Bubbles: The First Test," Journal of Political Economy, 88, No. 4 (August), 745-770.

Friedman, Benjamin [1977], "The Inefficiency of Short-Run Monetary Targets for Monetary Policy," Brookings Papers on Economic Activity, 293-335. Klein, Benjamin M. [1977], "The Demand for Quality-Adjusted Cash Balances: Price Uncertainty in the U.S. Demand for Money Function," Journal of Political Economy, 85, No. 4 (August), 691-715.

Lucas, Robert E. [1976], "Econometric Policy Evaluation: A Critique," in The Phillips Curve and Labor Markets, edited by K. Brunner and A. H. Meltzer, the Carnegie-Rochester Conference Series, Vol. 1, $19-46$.

Lucas, Robert E. [1978], "Asset Prices in an Exchange Economy," Econometrica, 46 (November), 1429-1445.

McCafferty, S. and R. Driskill [1980], "Problems of Existence and Uniqueness in Non-Linear Models of Rational Expectations," Econometrica, 48 (July), 1313-1317.

McCallum, Bennett T. [1980], "Rational Expectations and Macroeconomic Stabilization Policy: · An Overview," Journal of Money, Credit, and Banking, 12 (November, pt. 2), 716-746.

McCallum, Bennett T. [1981], "Price Level Determinancy With an Interest Rate Policy Rule and Rational Expectations," Journal of Monetary Economics, 8 (November), 319-329.

McCallum, Bennett T. and James G. Hoehn [1981], "Money Stock Control With Reserve and Interest Rate Instruments Under Rational Expectations," 
mimeo (October).

McCallum, B. T. and J. K. Whitaker [1979], "The Effectiveness of Fiscal

Feedback Rules and Automatic Stabilizers Under Rational Expectations," Journal of Monetary Economics, 5 (April), 171-186.

Poole, William [1970], "Optimal Choice of Monetary Policy Instruments in a Simple Macro Mode1," Quarterly Joumal of Economics, 84 (May), 197-216. Santemero, A. M. and J. J. Seater [1981], "Partial Adjustment in the Demand for Money: Theory and Empirics," American Economic Review, 71 (September), 566-578.

Sargent, Thomas J. and Neil Wailace [1975], "'Rational' Expectations, the Optimal Monetary Instrument, and the Optimal Money Supply Rule," Journal of Political Economy, 83 (April), $241-254$.

Taylor, John B. [1975], "Monetary Policy During a Transition to Rational Expectations," Journal of Political Economy, 83 (October), 1009-1021. Taylor, John B. [1979], "Estimation and Control of a Macroeconomic Mode1 With Rational Expectations," Econometrica, 47 (September), 1267-1286. Tinsley, Peter A., Peter von zen Muehlen, Warren Trepeta, and Gerhard Fries [1981], "Money Market Impacts of Alternative Operating Procedures," Federal Reserve Staff Study, New Monetary Control Procedures, Vol. II (February).

Tobin, James [1958], "Liquidity Preference as Behavior Towards Risk," Review of Economic Studies, 25 (February), 65-86.

Walsh, Carl E. [1982], "The Demand for Money Under Uncertainty and the Role of Monetary Policy," mimeo (March).

Weber, Warren E. [1981], "Output Variability Under Monetary Policy and 
Exchange Rate Rules," Journal of Political Economy, 89 (August), 733-751.

Woglom, Geoffrey [1979], "Rational Expectations and Monetary Policy in

a Simple Macroeconomic Mode1," Quarterly Journal of Economics, 93 (February), 91-105. 